\title{
Vitamin supplement use among children with Down syndrome and risk of leukemia: A Children's Oncology Group (COG) Study
}

\author{
Cindy K. Blaira,b, Michelle Roesler ${ }^{a, b}$, Yang Xie ${ }^{b}$, Alan S. Gamis ${ }^{c}$, Andrew F. Olshan $^{d}$, Nyla \\ A. Heerema ${ }^{e}$, Leslie L Robison ${ }^{\dagger}$, and Julie A. Ross ${ }^{a, b, g}$ \\ aUniversity of Minnesota Cancer Center \\ bDivision of Pediatric Epidemiology \& Clinical Research, Department of Pediatrics, University of \\ Minnesota, Minneapolis, MN \\ cThe Childrens Mercy Hospital, Kansas City, Missouri \\ dDepartment of Epidemiology, University of North Carolina, Chapel Hill, North Carolina \\ eDepartment of Pathology, Ohio State University, Columbus, $\mathrm{OH}$ \\ fDepartment of Epidemiology and Cancer Control, St. Jude Children's Research Hospital, \\ Memphis, TN
}

\section{Summary}

\begin{abstract}
Vitamin supplements have been proposed for children with Down syndrome (DS) with claims of improving cognitive abilities, or immune or thyroid function. Several studies have shown decreased levels of zinc in this population. Because children with DS have a 50-fold increased risk of developing acute leukemia during the first 5 years of life, we explored the relation between child vitamin and herbal supplement use and the risk for leukemia in a case-control study. During the period 1997-2002, we enrolled 158 children with DS aged 0-18 years that were diagnosed with acute lymphoblastic leukemia (ALL) $(n=97)$ or acute myeloid leukemia (AML) $(n=61)$ at participating COG institutions. We enrolled 173 DS children without leukemia (controls), selected from the cases' primary care clinic and frequency matched on age. Data were collected via telephone interviews with mothers of the index child regarding use of multivitamins, zinc, vitamin $\mathrm{C}$, iron, and herbal supplements, including age at first use, frequency and duration. Among controls, 57\% reported regular multivitamin use ( 23 times/week for $\geq 3$ months) compared with $48 \%$ of ALL cases and $61 \%$ of AML cases. We found no evidence of an association between child's regular multivitamin use and ALL or AML (adjusted odds ratios (ORs) $=0.94$ [95\% confidence interval $0.52,1.70]$ and $1.90[0.73,4.91]$, respectively. There was a suggestion of an increased risk for AML associated with regular multivitamin use during the first year of life or for an extended duration (ORs $=2.38[0.94,5.76]$ and 2.59 [1.02, 6.59], respectively). Despite being the largest study of DS-leukemia, our sample size was small, resulting in imprecise effect estimates. Future research should include larger sample sizes as well as a full assessment of diet including vitamin supplementation to adequately examine the relation between nutritional status and childhood leukemia.
\end{abstract}

\section{Introduction}

Children with Down syndrome (DS) have an increased risk for congenital heart defects, thyroid dysfunction, gastrointestinal abnormalities, and immune system deficiencies

\footnotetext{
${ }^{9}$ To whom correspondence should be addressed: Dr. Julie Ross, Department of Pediatrics, MMC 422, 420 Delaware St. S.E., Minneapolis, MN 55455, Telephone: 612-626-2902, Fax: 612-626-4842, ross@epi.umn.edu.
} 
compared to children without DS. ${ }^{1-3}$ For many decades, vitamin and herbal supplements, in various doses and formulas, have been recommended for children with DS with claims of improving cognitive abilities or immune function or of alleviating thyroid or gastrointestinal dysfunction. Additionally, some studies have reported that children with DS are more prone to vitamin and mineral deficiencies. ${ }^{4}$ In particular, several studies have shown serum or plasma levels of zinc to be below normal in this population. ${ }^{5-7}$ Zinc deficiency, even at mild levels, may contribute to impairment of immune function..${ }^{8} 9$ Consequently, a large proportion of children with DS are given supplements, often within the first couple of years of life.

Children with DS below the age of five have a 40-fold increased risk of ALL and a 150-fold increased risk of myeloid leukemia. ${ }^{10}$ The role of trisomy 21 in DS leukemogenesis remains unknown. Since leukemia is much more common in this population, risk factors may be identified more readily. Investigation of acute leukemia in a population of children with DS may help elucidate the etiology of this disease, not only for these children, but also for children without DS. Since children with DS are targeted for vitamin supplement use, especially at an early age, and few risk factors have been identified for the increased risk of leukemia in this population, we performed an exploratory analysis to examine the association between child vitamin supplementation and the risk for acute leukemia in children with DS.

\section{Methods}

\section{Study Population}

Details of this study have been previously published. ${ }^{11,} 12$ Briefly, the cases were children with DS who were diagnosed with acute leukemia before age 20 between 1997 and 2002. They were identified through registration files of the Children's Oncology Group (COG), which consists of over 200 institutions. An estimated $94 \%$ of leukemia patients under age 15 and $73 \%$ under age 20 are treated at one of the COG institutions. ${ }^{13,14}$ Patients were eligible for the study if they resided in North America at the time of diagnosis, had an English speaking biological mother, and had a telephone in the home. Maternal interviews were successfully completed for 158 out of 210 leukemia patients identified through 116 COG institutions. Reasons for non-interview included maternal refusal (17\%), physician refusal $(5 \%)$, and inability to locate the mother (3\%).

Controls were identified through a roster of children with DS with no history of leukemia, provided by the primary care physician who treated one of the cases. Potential controls were randomly selected from the rosters and frequency matched to cases on age at leukemia diagnosis $(<1,1-3,4-6,7-10,11-14$, and 15-18 years). Of the 726 potential controls provided by the primary care clinics, 329 were randomly selected based on date of birth. The clinics were unable to provide contact information (names and addresses) for 114 children due to inability to contact the family $(n=46)$, refusal of clinic's request by the family $(n=19)$, ineligibility $(n=18)$, refusal to contact the family $(n=8)$, or other unreported reasons $(n=23)$. Of the 215 children for whom the clinics provided names and addresses, telephone interviews were successfully completed for 173 mothers $(80.5 \%)$. Reasons for non-interview include maternal refusal $(n=24)$, ineligibility $(n=9)$, or inability to schedule an interview $(\mathrm{n}=9)$. The Institutional Review Boards of the University of Minnesota and participating COG institutions have approved this study.

\section{Data Collection}

A structured, computer-assisted telephone questionnaire was administered by a trained interviewer to biological mothers of both cases and controls. The interview consisted of 
questions pertaining to sociodemographic factors, pregnancy history, as well as maternal and child medical history. In order to provide a similar time frame for childhood exposures among cases and controls, a reference date was assigned to each child prior to the interview. For cases, the reference date was six months prior to leukemia diagnosis. For controls, the reference date was a randomly selected day within 12 months of the child's birthday during the year of the frequency match. Mothers were asked about the index child's use of vitamin or herbal supplements from birth until the reference age. Information was collected specifically for multivitamins, zinc, vitamin $\mathrm{C}$, and iron supplements including age at first use, frequency and duration. A separate question assessed use of holistic or herbal treatments and/or supplements, allowing the mother to specify up to 3 different kinds.

\section{Statistical analyses}

The vitamin/herbal supplement questions were only asked of mothers whose index child had a reference age greater than one to allow for a latency period, thus 21 cases and 54 controls were excluded from the current analysis resulting in 137 cases (96 ALL; 41 AML) and 118 controls. Since there were varied responses to the question on herbal supplements, small numbers precluded assessment of individual supplements or categories of supplements (e.g., digestive aids, immune or cognitive boosters). Additionally, use of megatherapy supplements, such as NutriVene-D, was uncommon in our study participants and thus was not evaluated separately. Secondary analyses were conducted to further explore multivitamin use, since this was the most common type used. Herbal multi- or mega-vitamin formula supplements (NutriVene-D daily supplement, Maxilife COQ-10, and megavitamin not specified) were combined with regular multivitamins in these analyses. Regular multivitamin use was defined as using a multivitamin three or more times per week for at least three months. In order to assess the timing of the exposure, we estimated risks for leukemia associated with multivitamin use during the first year of life ( $\geq 3$ times per week for $\geq 1$ month). Additionally, we defined the post-natal window of exposure as the time since birth until the reference age. To account for reference age while evaluating duration of supplement use, we created a variable indicating whether the child used a multivitamin for more or less than one-half of the time during the window of exposure (duration ratio $=$ (stop date - start date)/reference age).

The association between vitamin use among children with DS and acute leukemia was estimated using unconditional logistic regression. The following variables were examined as potential confounders: maternal sociodemographic factors (age, education, ethnicity, and household income), maternal vitamin use before and during index pregnancy, breast feeding, and child characteristics (gender, birthweight, birth order, and reference age). Covariates were only retained in the final multivariable regression model if they modified the risk estimate by $10 \%$ or greater. Multivariable-adjusted analyses were performed to estimate the odds ratios (OR) and 95\% confidence intervals (95\% CI). All statistical tests were 2-sided. Analyses were conducted for acute leukemia combined as well as stratified on leukemia subtype (ALL and AML).

\section{Results}

In this case-control study of 137 DS-leukemia cases and 118 DS-controls, $56.9 \%$ of cases and $57.6 \%$ of controls were reported to have used a multivitamin compared with 30\%-54\% of US children. ${ }^{15-19}$ Among the multivitamin users, the majority started taking multivitamins during their first year of life (54\% controls, $69 \%$ cases) and took one or more a day ( $90 \%$ controls, $93 \%$ cases). Only $10.9 \%$ of controls and $7.3 \%$ of cases were using a non-multivitamin herbal supplement, such as Echinacea, Naturnicum, Silver, Ginko balboa, etc. 
Selected maternal and child characteristics are presented in Table 1. Compared with control mothers, cases mothers were more likely to be older $(235)$ at the index child's birth, but less likely to be Caucasian or to have completed education beyond high school. Mothers of ALL cases were less likely to have initiated multivitamin use before knowledge of index pregnancy. AML cases weighed more at birth compared with controls. While the mean age of ALL cases and controls was similar (5.9 vs. 6.3 years), the ALL cases were more likely to be in the $2-5$ year age group compared with controls. The AML cases were substantially more likely to be in the less than 2 year age group compared with controls (73\% vs. 19\%).

There was no evidence for an association between any multivitamin use or regular multivitamin use and acute leukemia, either ALL or AML (Table 2). The ORs for regular use of multivitamins were 0.94 [95\% CI 0.52, 1.70] for ALL and 1.90 [0.73, 4.91] for AML. Similarly, for the individual vitamins assessed in the interview, zinc, iron, and vitamin C, there was no statistically significant association with leukemia; however, the exposure prevalence was very low, thus resulting in wide confidence intervals. There were no appreciable changes in the estimates when the analyses were repeated for AML cases including only those controls less than five years of age.

Additional analyses were performed to account for timing and duration of childhood multivitamin use. ORs associated with regular multivitamin use during the first year of life ( $\geq 3$ times per week for $\geq 1$ month) were $1.43[0.75,2.71]$ for ALL and $2.38[0.94,5.76]$ for AML. When we examined the proportion of time during the post-natal exposure window (birth until reference age) that the child used a multivitamin supplement, we found no evidence for an association with ALL. Compared to children who did not take a multivitamin supplement, the ORs for ALL were 1.43 [0.74, 2.77] for children whose supplement use occurred for less than one-half the time and $1.06[0.50,2.23]$ for use occurring more than one-half of the time. However, there was an increased risk for AML among children who used a multivitamin for more than one-half of the duration of their post-natal exposure window ( $\mathrm{OR}=2.59[1.02,6.59])$ compared with non-users. The increased risk for AML was still elevated but somewhat attenuated when restricted to controls with reference age $\leq 5$ years for both timing and duration of multivitamin use.

When analyses were restricted to cases for whom controls were selected from the same clinic, there were no substantial differences with the possible exception of an increased risk of acute leukemia associated with any multivitamin use ( $\mathrm{OR}=2.73$, [95\% CI 1.19, 6.27]).

\section{Discussion}

The majority of studies that have examined vitamins and risk for childhood leukemia have focused on maternal use around the time of pregnancy, with several studies reporting a decreased risk of childhood ALL, ${ }^{20,21}$ including our current study. ${ }^{12}$ Two of these studies conducted in children without DS found a 30\% and 60\% decreased risk of ALL associated with maternal use of vitamins (type not specified) ${ }^{21}$ and folate supplementation with or without iron ${ }^{20}$, respectively. In a previous analysis of the current case-control study, we observed a reduced risk of ALL (OR 0.51, [95\% CI 0.30, 0.89]) but not AML (OR 0.92, [95\% CI 0.48, 1.76]) in children with DS whose mothers took vitamin supplements during the periconceptional period. ${ }^{12}$ Few studies have specifically evaluated the association between post-natal vitamin supplementation and subsequent development of childhood leukemia. Ours is the first to study this association among children with DS.

Several studies have evaluated child diet in relation to leukemia (excluding children with DS), focusing on $\mathrm{N}$-nitroso precursors found in some foods like cured meats that are thought to lead to carcinogen formation if not blocked. ${ }^{22-24}$ Only two of these studies assessed child 
vitamin use in addition to diet. In a case-control study, there was no significant association between childhood acute leukemia (mostly ALL) and use of vitamins during the first 2 years of life, with or without adjustment for child's diet ( $\mathrm{OR}=0.70$, [95\% CI $0.42,1.18]$; $\mathrm{OR}=0.88$, $[95 \%$ CI $0.59,1.31]$, respectively). ${ }^{22}$ In an earlier study, child vitamin use was evaluated as a confounder and effect modifier of meat consumption, with no mention of a risk estimate for vitamin intake alone. ${ }^{24}$ These studies only included assessment of certain foods and food groups, thus childhood leukemia research to date has not included in-depth assessment of child nutritional status.

While there is some evidence that vitamin supplementation may reduce the risk of selected adult malignancies, there are inconsistencies in the literature. In general, randomized clinical trials have not shown a significant protective effect, however, most trials have either included only high risk populations, examined a limited number of micronutrients, involved a limited duration of treatment or follow-up, or used high doses that far exceed the current recommended amount. ${ }^{25,26}$ The results among observational studies are inconclusive as well. ${ }^{26}$ Nonetheless, there is biologic plausibility for an effect of vitamin supplementation on cancer risk, although where it occurs along the continuum from protective to harmful is not yet known. Inadequate intake of important micronutrients may contribute to DNA damage, in the form of single or double stranded breaks or oxidative lesions, which may in turn contribute to cancer development. ${ }^{8,27}$ Additionally, undernutrition, either through insufficient intake of macro-and/or micro-nutrients may contribute to impairment of immune functioning. ${ }^{9,} 28$ On the other hand, supplement use among individuals at high risk of malignancy may promote carcinogenesis through either the proliferation or inhibition of apoptosis of mutated cells. In two large chemoprevention trials, there was an increased risk of incident lung cancer among heavy smokers and workers exposed to asbestos who received beta-carotene supplements compared with those who received a placebo. ${ }^{29}, 30$

In our study, we found the suggestion of a possible increased risk for AML, however, our sample size was small and the observed elevated ORs may have resulted from multiple comparisons. AML in children with DS is different demographically and biologically than AML in children without DS. Not only is AML more common among children with DS (about half of the leukemias), ${ }^{31,32}$ it also presents at an earlier age (median $=2$ years in DS vs. 8 years in non-DS children). ${ }^{33}$ The most common subtype of AML in children with DS is acute megakaryoblastic leukemia (AMKL), which is rare in non-DS children. More importantly, DS-AMKL is characterized by mutations in the hematopoietic transcription factor GATA1 and has a more favorable response to treatment compared with non-DSAMKL. ${ }^{34}$. Infants with DS are predisposed to transient myeloproliferative disorder (TMD), which usually regresses spontaneously. However, 20-30\% of TMD patients subsequently develop AMKL within the first four years of life. ${ }^{35}$ Interestingly, mutations in GATA1 are found in TMD blasts and AMKL blasts, but are not found in children without DS, except in cases with acquired trisomy 21 in their leukemic cells. ${ }^{31}$ There is evidence that GATA1 mutations, like TMD, can occur during fetal development. (reviewed in ${ }^{31}$ ) Since neither DS nor the GATA1 mutation are sufficient for development of AML, it is likely that postnatal events play a role.

While some studies have reported certain vitamin and mineral deficiencies in children with DS, many had major methodological problems such as small sample size, lack of controls, or short duration of follow-up. ${ }^{3,}{ }^{36}$ Consequently, there is no clear and consistent evidence to support vitamin supplementation in children with DS. However, the importance of adequate micronutrient intake on physiological, immunologic, or developmental processes for all children, regardless of susceptibility to micronutrient deficiencies, is undisputed. 
Despite being the largest case-control study of DS-leukemia, our sample size was small and the exposure prevalence of specific types of vitamins was low, thus limiting power to detect small risks. Nevertheless, for regular multivitamin use, with an exposure rate of 57\% in controls, at an alpha level of 0.05 , we had $85 \%$ power to detect an increased risk of 1.92 or a decreased risk of 0.54 . Thus, if there was a strong positive (2-fold or higher) or negative ( 0.5 or lower) association between regular multivitamin use and acute leukemia, we would have had sufficient power to detect such an association. While our data lacked information on vitamin dose, we did have information on frequency and duration of use. An additional limitation to the current analysis is the lack of dietary data for the case and control subjects, which would be needed to conduct a full assessment of nutrient intake.

There is a possibility of recall bias, as childhood use of vitamin supplements was reported by the mother. However, the high prevalence of multivitamin use in children during the past decade or two, especially in this population, might minimize the potential for substantial bias. As with most case-control studies, there is a potential for selection bias, particularly among controls. It is unlikely that our cases differed much from the population of children with DS since a child with DS diagnosed with leukemia in the United States would likely be referred to and treated at a COG institution, which treat $94 \%$ of all leukemia cases. ${ }^{13,14}$ Since the focus for this case-control study concerned maternal periconceptional exposures, only biological mothers were included in the study. Only five cases and nine controls were excluded, thus minimizing any potential selection bias due to this inclusion criterion. The potential for selection bias in this study is strongest for controls as there is no populationbased national registry for DS. Thirty-one percent of clinics refused or were unable to provide rosters of children with DS and contact information was not provided for $35 \%$ of the children selected as potential controls. However, among the controls referred to the study, the participation rate was high $(80 \%)$. Moreover, restricting analyses to only case children who had a control from the same clinic did not notably change the results.

Our results do not support a strong association between childhood vitamin use and risk of ALL among children with DS. In contrast, there is a suggestion of an increased risk of AML, particularly among those children who begin taking vitamins during their first year of life or take them for a long duration. Additional studies with larger sample sizes are needed to confirm these results. Prior studies have investigated the effect of maternal or child diet on childhood acute leukemia, though most involved a limited dietary questionnaire and few included vitamin supplementation. Additionally, the majority of studies on vitamin supplementation have examined maternal use during the periconceptional period. In order to adequately examine the association between nutritional status and childhood leukemia risk, future studies should include a complete assessment of both maternal and child diet including vitamin supplementation.

\section{Acknowledgments}

This work was supported by NIH grants R01 CA75169 and U10 CA098543, the University of Minnesota Children's Cancer Research Fund and in part by a grant from the National Institute of Environmental Health Sciences (P30ES10126). A complete listing of grant support for research conducted by CCG and POG before initiation of the COG grant in 2003 is available online at:

http://www.childrensoncologygroup.org/admin/grantinfo.htm

\section{References}

1. Van Cleve SN, Cohen WI. Part I: clinical practice guidelines for children with Down syndrome from birth to 12 years. Journal of Pediatric Health Care. 2006; 20:47-54. [PubMed: 16399479]

2. Roizen NJ, Patterson D. Down's syndrome. Lancet. 2003; 361:1281-1289. [PubMed: 12699967] 
3. Ani C, Grantham-McGregor S, Muller D. Nutritional supplementation in Down syndrome: theoretical considerations and current status. Developmental Medicine and Child Neurology. 2000; 42:207-213. [PubMed: 10755461]

4. Palmer S. Influence of vitamin A nutriture on the immune response: findings in children with Down's syndrome. International Journal for Vitamin and Nutrition Research. 1978; 48:188-216. [PubMed: 151083]

5. Stabile A, Pesaresi MA, Stabile AM, Pastore M, Sopo SM, Ricci R, et al. Immunodeficiency and plasma zinc levels in children with Down's syndrome: a long-term follow-up of oral zinc supplementation. Clinical Immunology and Immunopathology. 1991; 58:207-216. [PubMed: 1824686]

6. Purice M, Maximilian C, Dumitriu I, Ioan D. Zinc and copper in plasma and erythrocytes of Down's syndrome children. Endocrinologie. 1988; 26:113-117. [PubMed: 2970667]

7. Licastro F, Mocchegiani E, Zannotti M, Arena G, Masi M, Fabris N. Zinc affects the metabolism of thyroid hormones in children with Down's syndrome: normalization of thyroid stimulating hormone and of reversal triiodothyronine plasmic levels by dietary zinc supplementation. International Journal of Neuroscience. 1992; 65:259-268. [PubMed: 1341688]

8. Ames BN. DNA damage from micronutrient deficiencies is likely to be a major cause of cancer. Mutation Research. 2001; 475:7-20. [PubMed: 11295149]

9. Costello RB, Grumstrup-Scott J. Zinc: what role might supplements play? Journal of the American Dietetic Association. 2000; 100:371-375. [PubMed: 10719417]

10. Hasle H, Clemmensen IH, Mikkelsen M. Risks of leukaemia and solid tumours in individuals with Down's syndrome. Lancet. 2000; 355:165-169. [PubMed: 10675114]

11. Canfield KN, Spector LG, Robison LL, Lazovich D, Roesler M, Olshan AF, et al. Childhood and maternal infections and risk of acute leukaemia in children with Down syndrome: a report from the Children's Oncology Group. British Journal of Cancer. 2004; 91:1866-1872. [PubMed: 15520821]

12. Ross JA, Blair CK, Olshan AF, Robison LL, Smith FO, Heerema NA, et al. Periconceptional vitamin useand leukemia risk in children with Down syndrome: a Children's Oncology Group study. Cancer. 2005; 104:405-410. [PubMed: 15952191]

13. Ross JA, Severson RK, Pollock BH, Robison LL. Childhood cancer in the United States. A geographical analysis of cases from the Pediatric Cooperative Clinical Trials groups. Cancer. 1996; 77:201-207. [PubMed: 8630931]

14. Liu L, Krailo M, Reaman GH, Bernstein L. Childhood cancer patients' access to cooperative group cancer programs: a population-based study. Cancer. 2003; 97:1339-1345. [PubMed: 12599243]

15. Briefel R, Hanson C, Fox MK, Novak T, Ziegler P. Feeding Infants and Toddlers Study: do vitamin and mineral supplements contribute to nutrient adequacy or excess among US infants and toddlers? Journal of the American Dietetic Association. 2006; 106:S52-65. [PubMed: 16376630]

16. Eichenberger Gilmore JM, Hong L, Broffitt B, Levy SM. Longitudinal patterns of vitamin and mineral supplement use in young white children. Journal of the American Dietetic Association. 2005; 105:763-772. quiz 773-764. [PubMed: 15883554]

17. Balluz LS, Kieszak SM, Philen RM, Mulinare J. Vitamin and mineral supplement use in the United States. Results from the third National Health and Nutrition Examination Survey. Archives of Family Medicine. 2000; 9:258-262. [PubMed: 10728113]

18. Ervin RB, Wright JD, Reed-Gillette D. Prevalence of leading types of dietary supplements used in the Third National Health and Nutrition Examination Survey, 1988-94. Advance Data. 2004:1-7.

19. Yu SM, Kogan MD, Gergen P. Vitamin-mineral supplement use among preschool children in the United States. Pediatrics. 1997; 100:E4. [PubMed: 9346998]

20. Thompson JR, Gerald PF, Willoughby ML, Armstrong BK. Maternal folate supplementation in pregnancy and protection against acute lymphoblastic leukaemia in childhood: a case-control study. Lancet. 2001; 358:1935-1940. [PubMed: 11747917]

21. Wen W, Shu XO, Potter JD, Severson RK, Buckley JD, Reaman GH, et al. Parental medication use and risk of childhood acute lymphoblastic leukemia. Cancer. 2002; 95:1786-1794. [PubMed: 12365028] 
22. Kwan ML, Block G, Selvin S, Month S, Buffler PA. Food consumption by children and the risk of childhood acute leukemia. American Journal of Epidemiology. 2004; 160:1098-1107. [PubMed: 15561989]

23. Peters JM, Preston-Martin S, London SJ, Bowman JD, Buckley JD, Thomas DC. Processed meats and risk of childhood leukemia (California, USA). Cancer Causes and Control. 1994; 5:195-202. [PubMed: 8167267]

24. Sarasua S, Savitz DA. Cured and broiled meat consumption in relation to childhood cancer: Denver, Colorado (United States). Cancer Causes and Control. 1994; 5:141-148. [PubMed: 8167261]

25. Woodside JV, McCall D, McGartland C, Young IS. Micronutrients: dietary intake v. supplement use. Proceedings of the Nutrition Society. 2005; 64:543-553. [PubMed: 16313697]

26. Patterson RE, White E, Kristal AR, Neuhouser ML, Potter JD. Vitamin supplements and cancer risk: the epidemiologic evidence. Cancer Causes and Control. 1997; 8:786-802. [PubMed: 9328202]

27. Ames BN. Micronutrient deficiencies. A major cause of DNA damage. Annals of the New York Academy of Sciences. 1999; 889:87-106. [PubMed: 10668486]

28. Calder PC, Kew S. The immune system: a target for functional foods? British Journal of Nutrition. 2002; 88 (Suppl 2):S165-177. [PubMed: 12495459]

29. Omenn GS, Goodman GE, Thornquist MD, Balmes J, Cullen MR, Glass A, et al. Effects of a combination of beta carotene and vitamin A on lung cancer and cardiovascular disease. New England Journal of Medicine. 1996; 334:1150-1155. [PubMed: 8602180]

30. The Alpha-Tocopherol BCCPSG. The effect of vitamin E and beta carotene on the incidence of lung cancer and other cancers in male smokers. New England Journal of Medicine. 1994; 330:1029-1035. [PubMed: 8127329]

31. Crispino JD. GATA1 mutations in Down syndrome: implications for biology and diagnosis of children with transient myeloproliferative disorder and acute megakaryoblastic leukemia. Pediatric Blood and Cancer. 2005; 44:40-44. [PubMed: 15390312]

32. Gurbuxani S, Vyas P, Crispino JD. Recent insights into the mechanisms of myeloid leukemogenesis in Down syndrome. Blood. 2004; 103:399-406. [PubMed: 14512321]

33. Lange BJ, Kobrinsky N, Barnard DR, Arthur DC, Buckley JD, Howells WB, et al. Distinctive demography, biology, and outcome of acute myeloid leukemia and myelodysplastic syndrome in children with Down syndrome: Children's Cancer Group Studies 2861 and 2891. Blood. 1998; 91:608-615. [PubMed: 9427716]

34. Bourquin JP, Subramanian A, Langebrake C, Reinhardt D, Bernard O, Ballerini P, et al. Identification of distinct molecular phenotypes in acute megakaryoblastic leukemia by gene expression profiling. Proceedings of the National Academy of Sciences of the United States of America. 2006; 103:3339-3344. [PubMed: 16492768]

35. Zipursky A. Transient leukaemia--a benign form of leukaemia in newborn infants with trisomy 21 . British Journal of Haematology. 2003; 120:930-938. [PubMed: 12648061]

36. Sacks, B.; Buckley, F. Down Syndrome News \& Update. Vol. 1. The Down Syndrome Educational Trust; Multi-nutrient Formulas and Other Substances as Therapies for Down Syndrome: An Overview; p. 70-83. 


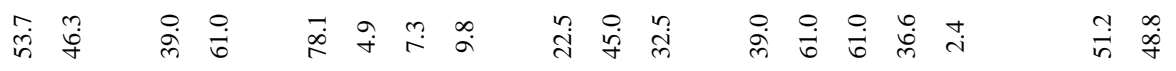

ส 90

लाN

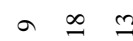

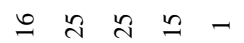

$\overline{4}$

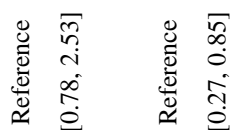

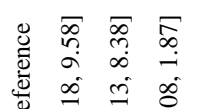

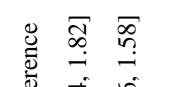

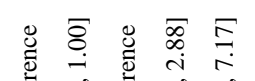

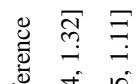

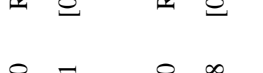

0 車

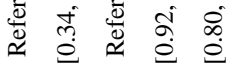

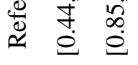

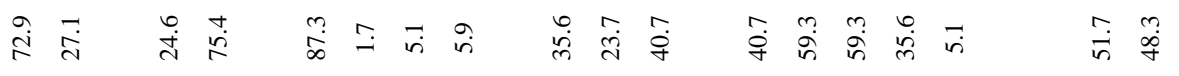
$\infty$ กี के 
Blair et al.

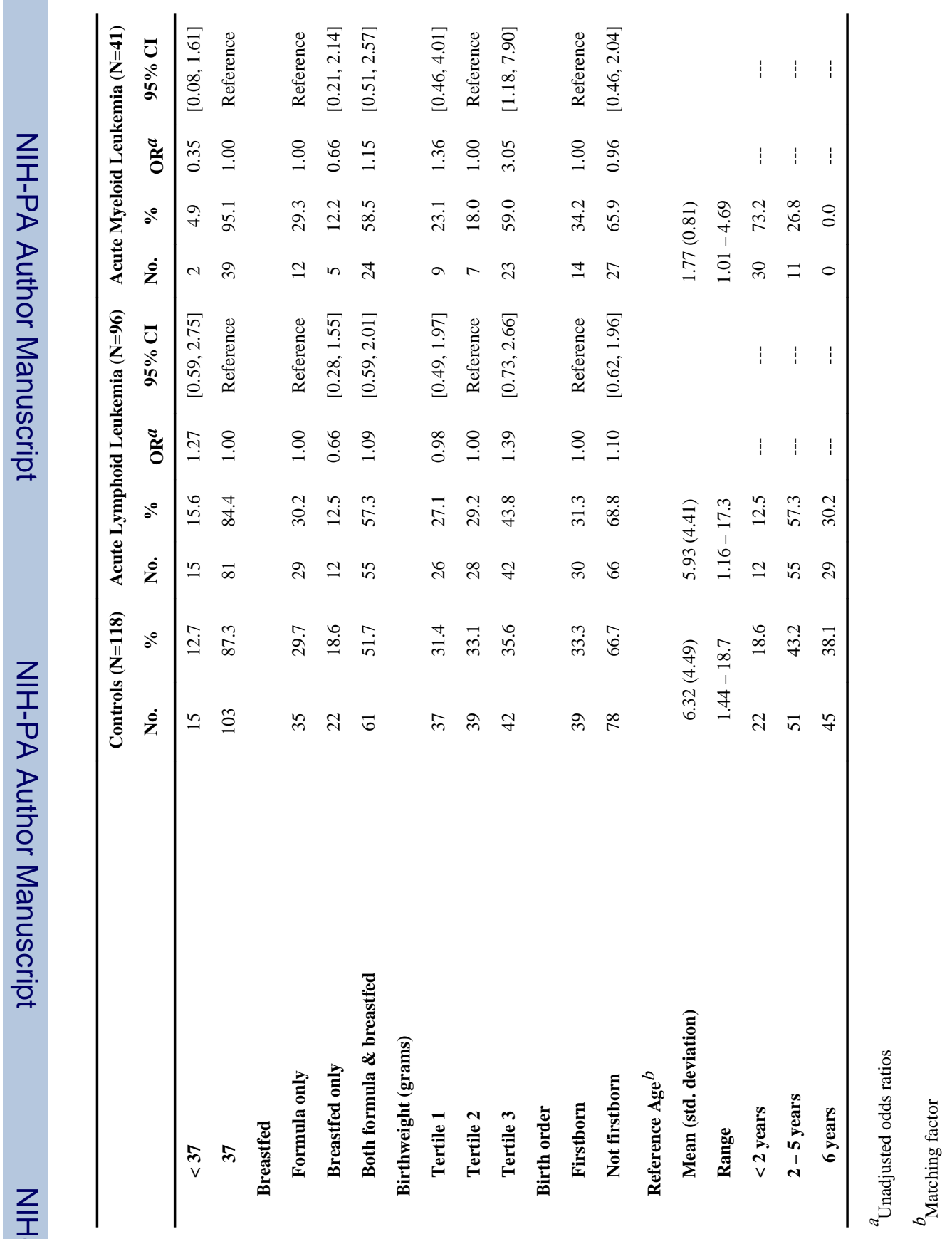




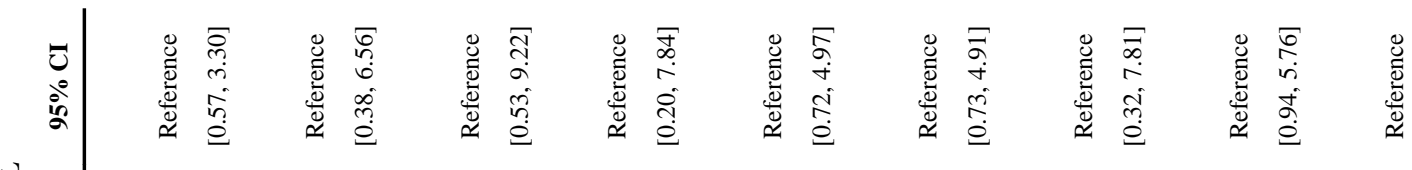

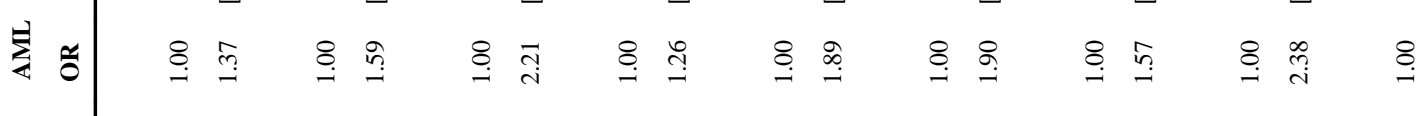

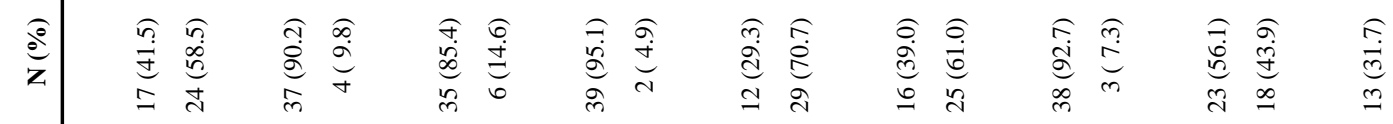

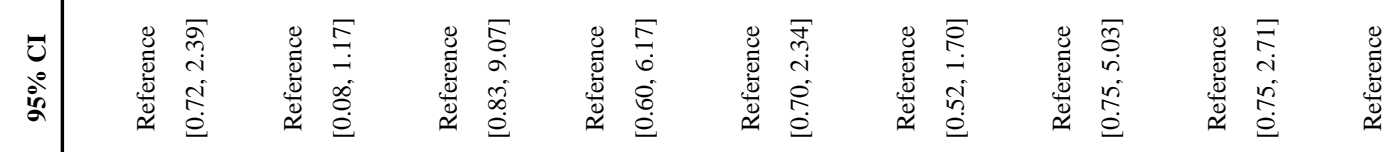

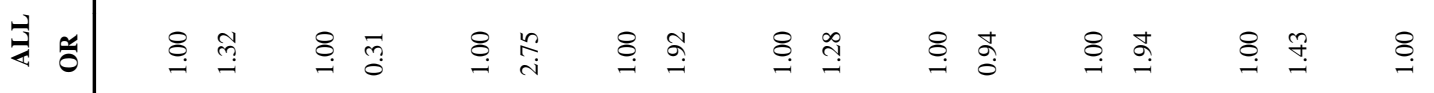

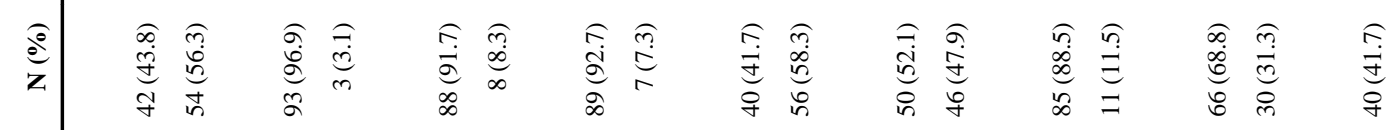

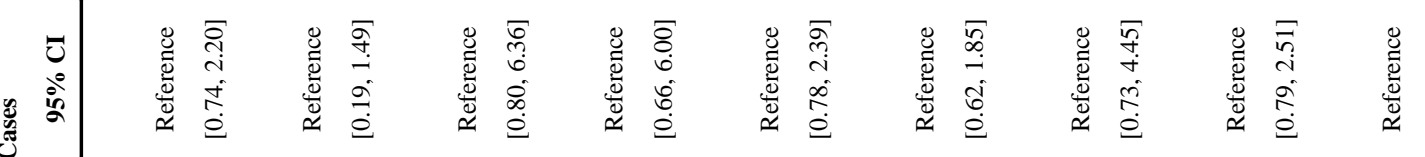

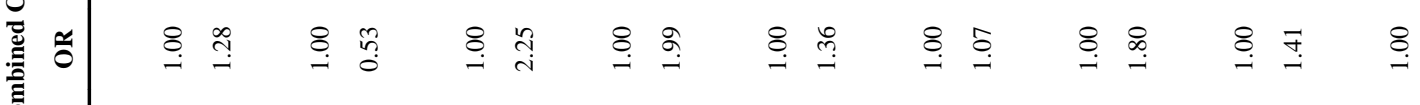

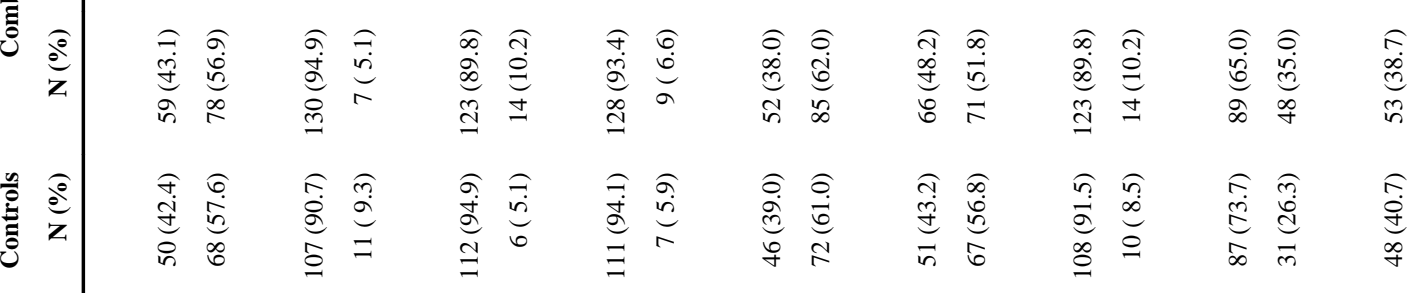

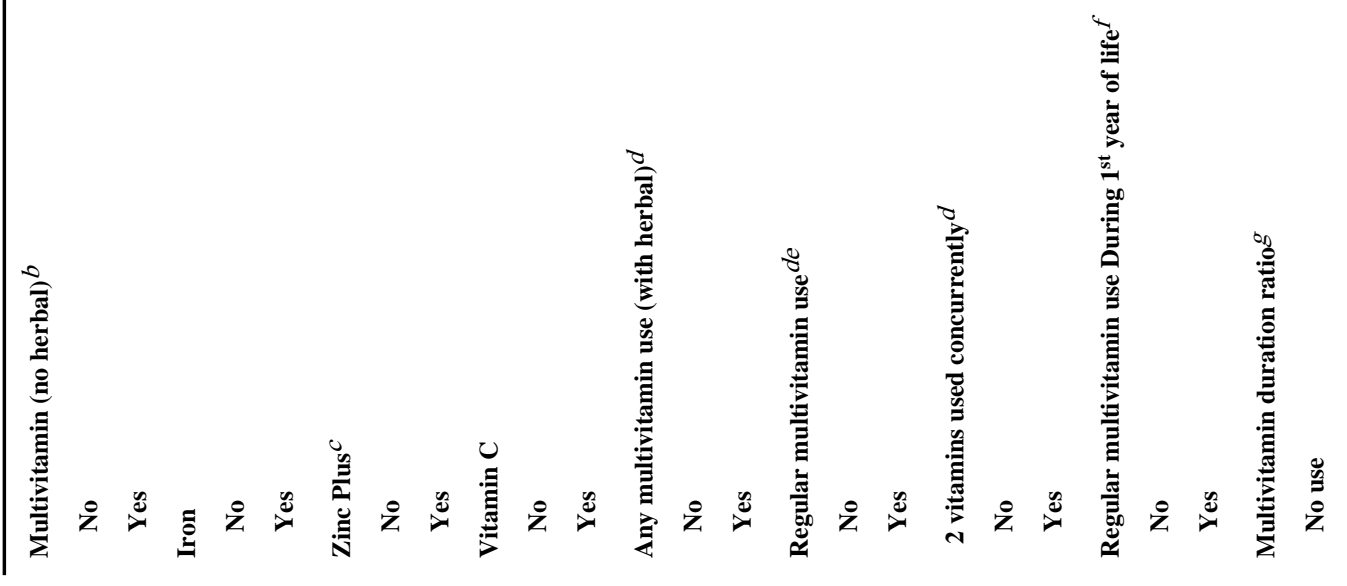

Paediatr Perinat Epidemiol. Author manuscript; available in PMC 2012 June 01. 


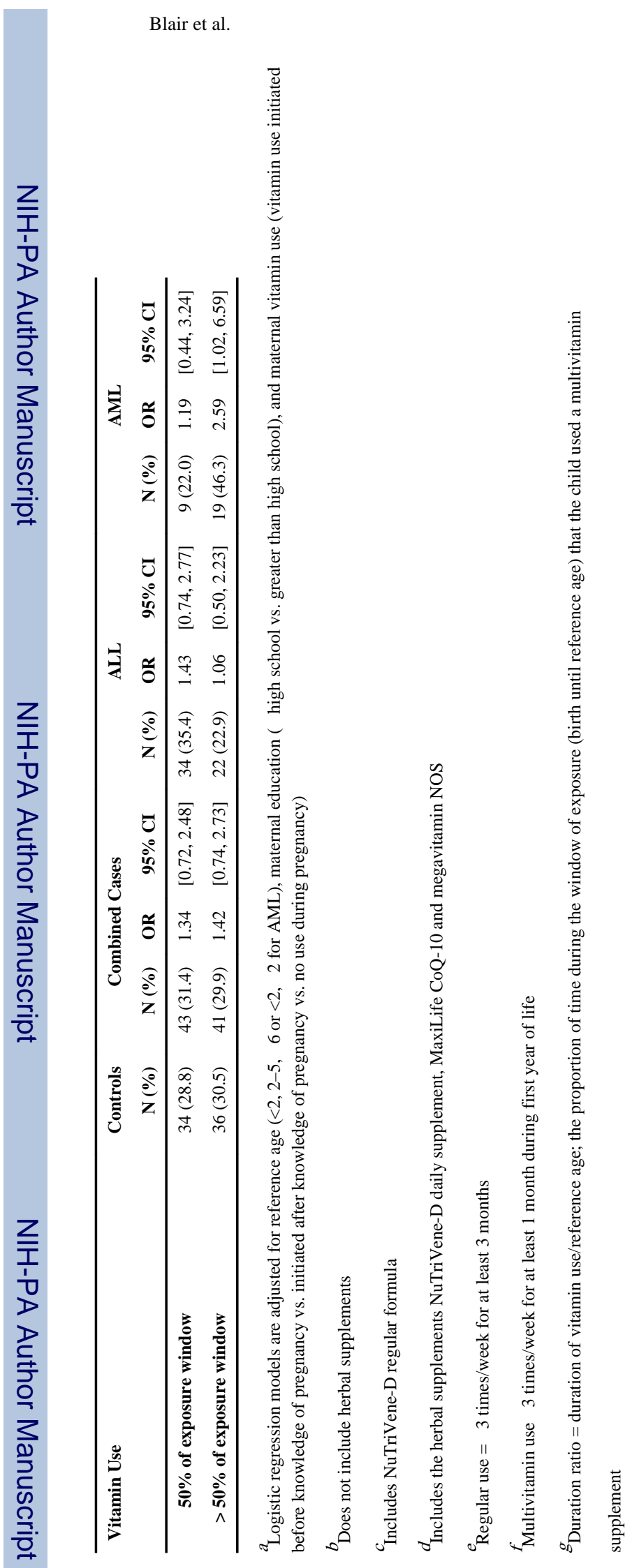

Paediatr Perinat Epidemiol. Author manuscript; available in PMC 2012 June 01. 